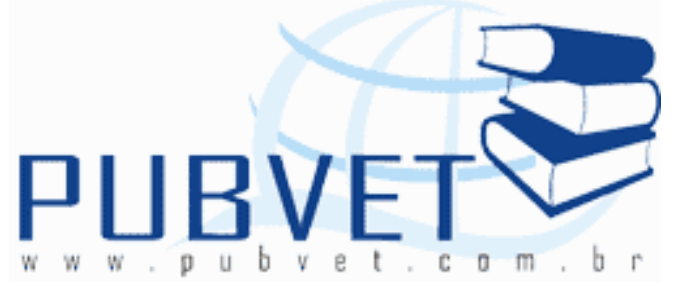

PUBVET, Publicações em Medicina Veterinária e Zootecnia.

\title{
Estabelecimento de Acacia angustissima em pastagens de Brachiaria brizantha cv. Marandu em Porto Velho, Rondônia
}

Claudio Ramalho Townsend ${ }^{1}$, João Avelar Magalhães ${ }^{2}$, Ricardo Gomes de Araujo Pereira ${ }^{1}$, Newton de Lucena Costa ${ }^{3}$

${ }^{1}$ Zootecnista, D.Sc., Embrapa Rondônia. Porto Velho, Rondônia.

2 Méd. Vet., D.Sc., Embrapa Meio-Norte. Parnaíba, Piauí.

${ }^{3}$ Eng. Agrôn., D.Sc., Embrapa Roraima. Boa Vista, Roraima.

\section{Resumo}

Avaliou-se o estabelecimento da Acacia angustissima em pastagens de Brachiaria brizantha cv. Marandu. O delineamento experimental foi em blocos ao acaso, utilizando-se como tratamentos as densidades de plantio correspondentes a 5, 15 e 30\% da área de pastagem, com quatro repetições. A taxa de sobrevivência do componente arbóreo foi decrescente, passando de $76 \%$ no início, para $64 \%$ ao final do experimento, em função dos danos causados pelos bovinos em pastejo. Assim, para introdução de A. angustissima em pastagens de $B$. brizantha $\mathrm{cv}$. Marandu, as árvores deverão receber algum tipo de proteção a fim de evitar danos causados por bovídeos em pastejo, principalmente durante o estabelecimento inicial.

Palavras-chave: altura, diâmetro, sobrevivência 


\title{
Establishment of Acacia angustissima in pastures of Brachiaria brizantha cv. Marandu in Porto Velho, Rondônia
}

\begin{abstract}
It was evaluated the establishment of Acacia angustissima in pastures of Brachiaria brizantha cv. Marandu. The experimental design was a randomized block design, using treatments like the following planting densities 5, 15 and $30 \%$ of pasture area with four replications. The survival rate of the tree component was decreasing, from $76 \%$ at baseline to $64 \%$ at the end of experimental period, depending on the damage caused by grazing cattle. Thus, for introducing of $A$. angustissima in pastures of $B$. brizantha cv. Marandu, the trees should receive some kind of protection to prevent damage caused by bovine grazing, especially during the initial establishment.
\end{abstract}

Keywords: height, diameter, survival

\section{Introdução}

Nas últimas décadas, a pecuária tem apresentado um acelerado crescimento na região Amazônica. Em Rondônia, o efetivo aumentou consideravelmente, passando de 650.000 bovinos em 1984, para 12.212.647, em 2012 (MAPA, 2012), representando um dos mais importantes segmentos de sua economia. A base alimentar destes rebanhos constitui-se de pastagens cultivadas, que via de regra, são estabelecidas em áreas sob vegetação de florestas, após a derrubada e queima da exuberante biomassa. Neste processo, não há a preocupação por parte dos pecuaristas, de manter algumas espécies arbustivas, a fim de propiciarem sombra aos animais.

Na Amazônia, onde a temperatura e a umidade relativa do ar são elevadas, o estresse térmico causado aos animais em pastejo, deprime o consumo voluntário, refletindo negativamente sobre o desempenho dos mesmos. O sombreamento de pastagens, através do estabelecimento de 
espécies arbóreas, tem sido bastante apregoado a fim de minimizar os efeitos adversos do clima sobre os bovídeos (VEIGA \& SERRÃO, 1990).

Por tratar-se de uma leguminosa que apresenta rápido crescimento, associada a elevadas taxas de sobrevivência (LOCATELLI et al., 1992; COSTA et al., 1998), bem como, aos seus teores de proteína bruta próximos a $20 \%$, têm despertado o interesse da utilização da Acacia angustissima no processo de arborização de pastagens. No entanto, Dzowela (1994) adverte que sua utilização como forrageira pode ser limitada em função das elevadas concentrações de taninos $(23,2 \%)$, o que reflete negativamente sobre a sua palatabilidade e digestibilidade.

Este trabalho teve por objetivo avaliar o estabelecimento da $A$. angustissima, sob diferentes densidades de plantio, em pastagens de $B$. brizantha cv. Marandu.

\section{Material e Métodos}

O experimento foi conduzido na Embrapa Rondônia, em Porto Velho, onde o clima é do tipo tropical úmido com pluviosidade anual oscilando entre 2.000 e 2.300 mm, ocorrendo déficit hídrico durante os meses de junho a setembro, a umidade relativa do ar média é de $89 \%$ e as temperaturas médias anuais são de 32,0 e $20,4^{\circ} \mathrm{C}$, para máximas e mínimas, respectivamente.

O solo da área experimental foi classificado como Latossolo Amarelo, textura argilosa, com as seguintes características químicas: $\mathrm{pH}=5,0 ; \mathrm{P}=2$ $\mathrm{ppm} ; \mathrm{K}=0,06 \mathrm{meq} / 100 \mathrm{~g} ; \mathrm{Ca}+\mathrm{Mg}=1,63 \mathrm{meq} / 100 \mathrm{~g} ; \mathrm{Al}+\mathrm{H}=13,8$ meq $/ 100 \mathrm{~g}$ e $M O=2,04 \%$.

Como componente arbóreo do sistema, optou-se pela $A$. angustissima, o plantio se deu através de covas de $20 \times 20 \times 40 \mathrm{~cm}$, adubadas com $50 \mathrm{~g}$ de superfosfato triplo e aproximadamente $2 \mathrm{~kg}$ de esterco bovino curtido, mantendo-se o espaçamento de $6 \mathrm{~m} \times 6 \mathrm{~m}$ entre covas, distribuídas em quatro bosques em cada um dos pastos, conforme as densidades de plantio de 5, 15 e 
TOWNSEND, C.R. et al. Estabelecimento de Acacia angustissima em pastagens de Brachiaria brizantha cv. Marandu em Porto Velho, Rondônia. PUBVET, Londrina, V. 7, N. 22, Ed. 245, Art. 1617, Novembro, 2013.

$30 \%$ da área de pastagens de $B$. brizantha cv. Marandu, formadas há mais de cinco anos.

Após o plantio das árvores, as pastagens permaneceram vedadas ao pastejo até que a acácia apresentasse desenvolvimento adequado, ou seja, quando as copas das árvores atingiram altura superior ao alcance dos animais em pastejo. Procedeu-se capina ao redor das árvores e o roço das pastagens, quando necessário.

Townsend et al. (1998) manejaram estes sistemas silvipastoris com novilhos bubalinos e constataram que decorridos 90 dias os animais causaram danos em cerca de $46 \%$ das plantas, injúrias que foram desde alguns galhos quebrados até o tombamento das plantas, sem no entanto, perceberem sinais evidentes de ramoneo (consumo das copas das árvores pelos animais), o que determinou a interrupção do pastejo e poda de todas as árvores, a altura de $1,0 \mathrm{~m}$ da superfície do solo, a fim de uniformizá-las.

Após o restabelecimento do componente arbóreo, os sistemas voltaram a ser avaliados. Para tanto, foram utilizadas 18 novilhas mestiças Holando $\mathrm{x}$ Zebu, com peso vivo (PV) médio inicial de $250 \mathrm{~kg}$, distribuídas nos três tratamentos. Durante os 209 dias (05/01/99 a 04/08/99), os sistemas foram manejados sob pastejo contínuo, mantendo-se a carga animal próxima a 1 UA (450 kg de PV/ha).

Para análise de variância empregou-se o delineamento experimental blocos ao acaso, com quatro repetições, sendo avaliados os parâmetros de altura de planta, diâmetros basal e à altura do peito (DAP) da leguminosa, aos 23 e 46 meses de idade.

\section{Resultados e Discussão}

A altura média das plantas da $A$. angustissima tomadas aos 23 meses (Tabela 1), comparativamente aos 46 meses (Tabela 2), decresceu, passando de 366 para $233 \mathrm{~cm}$, já que as árvores foram submetidas à poda, cerca de 12 
TOWNSEND, C.R. et al. Estabelecimento de Acacia angustissima em pastagens de Brachiaria brizantha cv. Marandu em Porto Velho, Rondônia. PUBVET, Londrina, V. 7, N. 22, Ed. 245, Art. 1617, Novembro, 2013.

meses antes da segunda avaliação. O diâmetro da base e o DAP das árvores estabelecidas na menor densidade apresentaram incrementos de 18 e 31\%, respectivamente; para a densidade de $15 \%$ não ocorreram variações significativas, enquanto que na densidade de $30 \%$ o diâmetro basal foi incrementado em $2 \%$ e o DAP reduzido em $11 \%$, em função do grau de injúrias causados pelos bubalinos nas avaliações anteriores, que foram de 46, 25 e 66\% das plantas para densidades de 5, 15 e 30\% da área da pastagem, respectivamente.

Tabela 1. Altura de planta, diâmetro basal e diâmetro a altura do peito (DAP) de Acacia angustissima aos 23 meses de estabelecimento sob diferentes densidades de plantio, em pastagens de Brachiaria brizantha cv. Marandu.

\begin{tabular}{cccc}
\hline Densidade de & Altura de planta & Diâmetro basal & DAP \\
\cline { 2 - 4 } plantio $(\%)^{1}$ & & $\mathrm{~cm}$ & \\
\hline 5 & $352 \mathrm{~b}$ & $4,53 \mathrm{~b}$ & $3,36 \mathrm{a}$ \\
15 & $380 \mathrm{a}$ & $4,99 \mathrm{ab}$ & $3,52 \mathrm{a}$ \\
30 & $365 \mathrm{ab}$ & $5,03 \mathrm{a}$ & $3,54 \mathrm{a}$ \\
\hline Média & 366 & 4,85 & 3,47 \\
\hline $\mathrm{CV}(\%)$ & 8 & 18 & 16 \\
\hline
\end{tabular}

${ }^{1}$ Percentagem da área de pastagem plantada com acácia

Médias seguidas de mesma letra não diferem entre si $(P>0,05)$ pelo teste de Tukey

Locatelli et al. (1992), sob as mesmas condições edafoclimáticas, verificaram que a $A$. angustissima na ausência de poda apresentou altura de 4,30 e 5,64 m aos 22 e 26 meses, respectivamente, com taxa de sobrevivência de $90 \%$. Enquanto que quando submetida à poda a um metro acima do solo, o porte das plantas diminui de 2,29 para 2,13 $\mathrm{m}$ e a sobrevivência para 85\%. Costa et al. (1998) obtiveram plantas aos 24 meses, com 7,98 m de altura e DAP de 5,80 cm. Em Minas Gerais, Carvalho (1997), avaliando $A$. angustissima estabelecida em associação com diferentes gramíneas e com as árvores recebendo proteção individual contra os possíveis danos causados por bovinos em pastejo, constatou que o porte das plantas foi de 2,95 e 3,94 m e o DAP de 3,00 e 5,36 cm aos dois e quatro anos de crescimento, respectivamente. 
TOWNSEND, C.R. et al. Estabelecimento de Acacia angustissima em pastagens de Brachiaria brizantha cv. Marandu em Porto Velho, Rondônia. PUBVET, Londrina, V. 7, N. 22, Ed. 245, Art. 1617, Novembro, 2013.

Tabela 2. Sobrevivência, altura de planta, diâmetro basal e diâmetro a altura do peito (DAP) de Acacia angustissima aos 46 meses de estabelecimento sob diferentes densidades de plantio, em pastagens de Brachiaria brizantha cv. Marandu

\begin{tabular}{|c|c|c|c|c|c|}
\hline \multirow{2}{*}{$\begin{array}{c}\text { Densidade } \\
\text { de plantio } \\
(\%)^{1}\end{array}$} & \multicolumn{2}{|c|}{ Sobrevivência (\%) } & $\begin{array}{l}\text { Altura de } \\
\text { planta }\end{array}$ & $\begin{array}{c}\text { Diâmetro } \\
\text { basal }\end{array}$ & DAP \\
\hline & Início & Final & & $\mathrm{cm}$ & \\
\hline 5 & 85 & 68 & $225 a$ & $5,33 a$ & $4,40 \mathrm{a}$ \\
\hline 15 & 77 & 61 & $250 a$ & $4,95 a$ & $3,78 a b$ \\
\hline 30 & 67 & 63 & $225 \mathrm{a}$ & $5,15 a$ & $3,13 \mathrm{~b}$ \\
\hline Média & 76 & 64 & 233 & 4,81 & 3,47 \\
\hline CV (\%) & & & 12 & 13 & 12 \\
\hline
\end{tabular}

${ }^{1}$ Percentagem da área de pastagem plantada com acácia.

Médias seguidas de mesma letra não diferem entre si $(P>0,05)$ pelo teste de Tukey

Para as três densidades de estabelecimento a taxa de sobrevivência do componente arbóreo foi decrescente (Tabela 2), passando em média de 76\% no início, para 64\% ao final, em função dos danos causados pelos bovinos em pastejo, bem como, pela incidência de cupins (Coptotermes havilandi), o que pode vir a comprometer a sua persistência.

\section{Conclusões}

$\mathrm{Na}$ introdução de $A$. angustissima em pastagens de Brachiaria brizantha CV. Marandu, as árvores deverão receber algum tipo de proteção a fim de evitar danos causados por bovídeos em pastejo, principalmente durante o estabelecimento inicial; caso contrário, estes sistemas deverão ser manejados sob pastejo com lotação rotacionada, que evitem danos e possibilitem o pleno estabelecimento do componente arbóreo.

\section{Referências Bibliográficas}

CARVALHO, M.M. Associaciones de pasturas com árboles en la región sur del Brasil. Agroforesteria en las Américas, v.4, n.5, p.5-8, 1997.

COSTA, N. de L.; LEÔNIDAS, F. das C.; TOWNSEND, C.R.; MAGALHÃES, J.A.; VIEIRA, A.H. Avaliação de leguminosas arbóreas e arbustivas de múltiplo uso em Rondônia. Porto Velho: EMBRAPA-CPAF Rondônia, 1998. 11p. (EMBRAPA-CPAF Rondônia. Boletim de Pesquisa, 27). 
MAPA - Ministério da Agricultura Pecuária e Abastecimento. Dados de rebanho bovino e bubalino do Brasil - 2012.2 Disponível em: <ttp://www.agricultura.gov.br/arq_editor/file/Dados\%20de\%20rebanho\%20bovino\%20e\%20 bubalino\%20do\%20Brasil_2012.pdf> Acesso: 20 de abril de 2013.

DZOWELA, B.H. Acacia angustissima: a central american tree that's going places. Agroforestry Today, v.4, n.3, p.13-14, 1994.

LOCATELLI, M.; VIEIRA, A.H.; PALM, C.A. Seleção de leguminosas para cultivo em "AlleyCropping" sob condições de latossolo amarelo. In: MESA REDONDA SOBRE RECUPERAÇÃO DE SOLOS ATRAVÉS DE LEGUMINOSAS, 1991. Trabalhos e recomendações... Belém: EMBRAPA/CPATU/GTZ, 1992. p.121-130. (EMBRAPA-CPATU. Documentos, 67).

TOWNSEND, C.R.; MAGALHÃES, J.A.; COSTA, N. de L.; PEREIRA, R.G. de A. Estabelecimento de Acacia angustissima, sob diferentes densidades em pastagens de Brachiaria brizantha cv. Marandu. In: CONGRESSO BRASILEIRO EM SISTEMAS AGROFLORESTAIS, 2., 1998, Belém. Anais... Belém: Embrapa Amazônia Oriental, 1998. p.221-223.

VEIGA, J.B.; SERRÃO, E.A.S. Sistemas silvipastoris e produção animal nos trópicos úmidos: a experiência da Amazônia brasileira. Campinas: SBZ/FEALQ, 1990. p.37-68. 